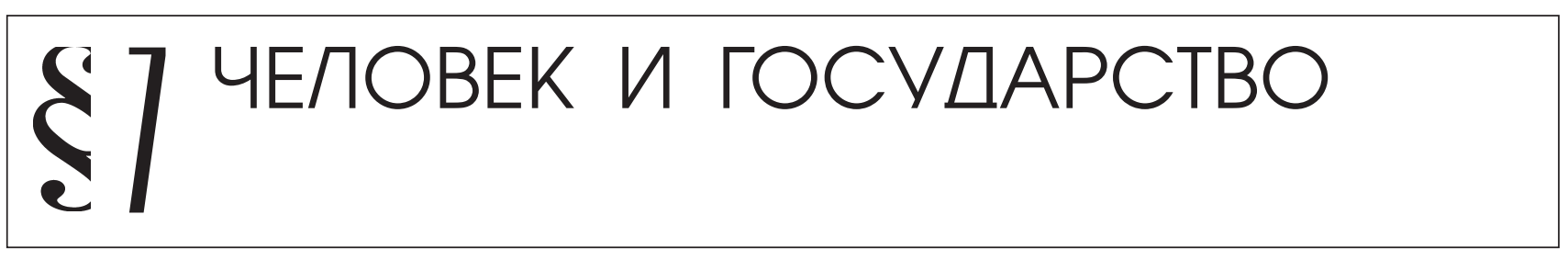

Мантулина О.О.

\title{
ОБЯЗАННОСТИ РОДИТЕЛЕЙ ПО СОДЕРЖАНИЮ НЕСОВЕРШЕННОЛЕТНИХ ДЕТЕЙ В РОССИИ И ЗАРУБЕЖНЫХ СТРАНАХ
}

Аннотация: В статье рассматриваются различные правовые аспекты обязанностей родителей по содержанию несовершеннолетних детей. Исследуется вопрос исторического становления данного института; определяется круг обязанных субъектов, уровень их ответственности и размер алиментов, а также условия наложения обязанностей по содержанию несовериеннолетних детей на родителей. Отмечаются сходства и различия в данном вопросе между странами англосаксонского и мусульманского права, а также романо-германской правовой семьи. Исследование проводится на примере российского, алжирского, марокканского, немецкого и калифорнийского семейного права. В статье использовались классические для юридической науки методь исследования. Основной упор сделан на использовании сравнительно-правового метода исследования. Обязанности родителей по содержанию несовершеннолетних детей являются общим для всех стран институтом семейного права, существующим с незапамятных времен. Основные отличия можно обнаружить между, с одной стороны, странами мусульманской правовой семьи, а, с другой сторонь, странами романо-германской и англосаксонской правовых семей. Данные различия выражаются в неравенстве полов (матери и отца) по отношению к обязательству по содержанию несовершеннолетних детей. В тоже время, данные различия довольно относительны.

Ключевые слова: Право, алименты, содержание, родители, дети, обязанность, несовершеннолетие, Россия, зарубежные страны, семейное право.

Abstract: This article examines various legal aspects of the parental responsibility to provide for their underage children. A research is conducted on the historical development of this institution, including determination of the circle of the responsible parties, level of their responsibility and size of the alimony, as well as the conditions under which the responsibility to support an underage child is placed upon a parent. The author notes the similarities and differences on this issue within the countries of Anglo-Saxon and Muslim laws, as well as the Romano-Germanic legal system. The research is conducted on the example of Russian, Algerian, Moroccan, German, and Californian family law. The parental responsibility to support their underage children is an institution that is common to family law of all countries, and has emerged over the recent past. The main distinctions can be found between the countries of Muslim legal system on one hand, and the countries of Roman-Germanic and Anglo-Saxon legal systems on the other. These distinctions are expressed in the inequality of genders (mother and father) with regards to responsibility to provide for their underage children, but at the same time, these differences are rather relative.

Keywords: Minors, responsibility, children, parents, support, alimony, law, Russia, foreign countries, family law.

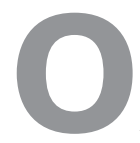

бязанности родителей по содержанию несовершеннолетних детей являются наиболее устоявшимся институтом семейного права любого современного государства. Более того, данный институт является настолько устоявшимся и естественным элементом семейных отношений, что мы обнаружим его на любой стадии развития общественных отношений, в том числе и существовавших в догосударственную эпоху. Иначе говоря, обязанность родителей по содержанию несовершеннолетних детей является социаль- ным институтом, имеющим внеправовую (или точнее, доправовую) природу, получившим свое закрепление в нормах морали, этики и религиозных принципах организации общественной и семейной жизни.

Наиболее ярким подтверждением данному утверждению могут служить религиозные принципы, которые по природе своей социоцентричны и устанавливают ряд обязательств, как в отношении общества, так и в отношении членов семьи. Действительно, практически любой религиозный текст содержит такого рода 
DOI: $10.7256 / 1811-9018.2015 .9 .16171$

При цитировании этой статьи сноска на доі обязательна

\section{Право и политика 9 (189) 2015}

обязательства родителей перед детьми. Так, например, Коран однозначно закрепляет обязанность родителей по содержанию своих детей: «И не давайте (о, попечители) легкомысленным (мужчинам, женщинам и детям) вашего имущества, которое Аллах устроил вам для поддержки, и наделяйте их из него, и одевайте их, и говорите им слово благое» [10]. Аналогичное подтверждение мы найдем и в христианских религиозных текстах: «Не дети должны собирать имение для родителей, но родители для детей» [11]. Таким образом, обязанность родителей по содержанию несовершеннолетних детей является наиболее ярким общественным институтом, имеющим без преувеличения универсальный характер (Так, например, Конвенция Организации Объединенных Наций “О правах ребенка” от 20 ноября 1989 года (Сборник международных договоров СССР. Выпуск XLVI, 1993) установила данную обязанность родителей как «..основную ответственность за обеспечение в пределах своих способностей и финансовых возможностей условий жизни, необходимых для развития ребенка" (n. 2, cm. 2), регулирующий семейные отношения с незапамятных времен и получивший свое закрепление в правовых нормах (в том числе канонического права) с появлением последних.

В правовом поле исследуемое обязательство было закреплено еще в римском праве. Действительно, Дигесты Юстиниана однозначно устанавливали обязанность родителей по содержанию детей: «Если же супруг откажется сделать то, что должен, то в любом случае принуждается содержать рожденного (ребенка), хотя он и может не признавать его сыном»[1]. По вполне объективным причинам, в русском праве данная обязанность была закреплена позднее, что не позволяет в тоже время отрицать ее существование и вне позитивного права, т.е. в рамках обычая, морали и религиозных норм. Действительно, первоначальное свидетельство о существовании в русском праве обязанности родителей по содержанию мы обнаружим лишь в пространной редакции Русской правды, где в частности указывается, что опекун «кормит и печалуется» [12] (т.е. заботиться) за детьми.

Сегодня, рассматриваемый институт нашел свое закрепление в ст. 80 Семейного кодекса Российской Федерации (Собрание законодательства Российской Федерации, 1996, № 1, cm. 16) в соответствии с которой: «Родители обязаны содержать своих несовершеннолетних детей». Речь идет именно о родителях, т.е. обязанность по содержанию детей возлагается на лиц, с которыми у последних существует юридическая связь (кровнородственная связь или усыновление (удочере- ние)), а обязанность в принципе накладывается, как на отца, так и на мать в равной мере (Наиболее ярко равенство родителей по отношению к обязанности по содержанию несовершеннолетних детей выражено в Калифорнийском семейном кодексе (California family code), где (\$ 3900) указывается что «...отеи и мать несовершеннолетнего несут равную ответственность за содержание ребенка...»).

Стоит обратить внимание на особенность семейного права отдельных мусульманских государств в данном вопросе, которую в принципе можно охарактеризовать как более патриархальный характер института обязанности родителей по содержанию несовершеннолетних детей. Действительно, в алжирском семейном кодексе (Cm. 64 алжирского семейного кодекса однозначна в данном вопросе: «опека над ребенком (hadana) вменяется в первую очередь матери... » См. Loi $N^{\circ}$ 84-11 portant Code de la Famille. Journal Officiel de la République algérienne, oct./nov. 1983, p. 612) данная обязанность возлагается только на отца (ст. 75), так как в традиционных мусульманских семьях именно отец является кормильцем семьи, а в случае развода дети не только на практике, но и с юридической точки зрения воспитываются лишь матерью (Так, в одном из судебных решений Верховного суда республики Алжир уточнялось, что в случае развода ребенок может остаться с отиом только в случае смерти матери и при условии, если интересы ребенка требуют этого, либо если органы опеки рекомендуют суду передать ребенка на воспитание отиу. См. Cour suprême, 12 février 2001, al-Madjalla al-qadâ'iyya, Alger, 2002, $n^{\circ} 2$, p. 421; Cour suprême, 18 février 1997, cité in Nasreddin Marrûk, Qânûn al-usra bayn al-nadhariyya wa al-tatbîq, Alger, Dâr al-Hilâl li-l-khadamât al-i'lâmiyya, 2204, p. 120) (ст. 64), тогда как все алиментные обязательства по содержанию детей возлагаются исключительно на отца. В тоже время, законодательство ряда более продвинутых в данном плане мусульманских государств свидетельствует о том, что в странах мусульманской правовой семьи все же существуют примеры более равного подхода к обязательству родителей по содержанию детей, т.е. аналогичных западным моделям семейного права институтов (Так, например, в соответствии с Марокканском семейным кодексом, обязательство по содержсанию детей вменяется в обязанность обоих родителей. См. $n .3 \mathrm{~cm} .54$ Марокканского семейного кодекса. Dahir $N^{\circ} 1-04-22$ du 12 Hija 1424 (3 février 2004) portant promulgation de la loi 70-03 portant Code de la famille, Bulletin Officiel $n^{\circ} 5358$ du 2 ramadan 1426 ( 6 octobre 2005 ), p. 667). 
Стоит отметить, что, если вопрос материнства по природе своей практически никогда не ставил проблем, т.е. определение обязанного субъекта в лице матери по обязательству содержания ребенка редко вызывало проблемы на практике, то вопрос определения отцовства на протяжении продолжительного времени создавал множество серьезных проблем в определении обязанного субъекта по обязательству содержания собственных несовершеннолетних детей. Действительно, в современном обществе количество детей, рождённых вне брака неуклонно растет, а вопросы установления отцовства, которые обуславливают выплату алиментов, т.е. обязательств по содержанию детей, становятся все более актуальными (Об этом в частности свидетельствует Постановление Пленума Верховного Суда РФ от 25 октября 1996 № 9 «О применении судами Семейного кодекса Российской Федерачии при рассмотрении дел об установлении отиовства и о взыскании алиментов» (Российская газета от 5 ноября 1996 г.), где в одном из первых пунктов рассматривается указанная проблема определения отиовства у лии не состоящих в браке (n. 3).). В тоже время, с появлением, так называемой экспертизы по вопросу о происхождении ребенка проведенной методом «генетической дактилоскопии» (П. 6 Постановления Пленума Верховного Суда РФ от 25 октября 1996 № 9 «О применении судами Семейного кодекса Российской Федерачии при рассмотрении дел об установлении отцовства и о взыскании алиментов»//Российская газета от 5 ноября 1996 г), проблемы установления отцовства, а, как следствие, и обязанного субъекта в отношениях содержания детей, были сняты. Это в частности отразилось на менее развернутом законодательном регулировании вопросов определения отцовства в современном законодательстве, где, в отличие например от Дигест Юстиниана, данному вопросу стало уделяться меньше внимания. Таким образом, можно утверждать, что в современном мире проблемы в вопросе определения обязанных субъектов в правоотношении по содержанию несовершеннолетних детей были практически сняты.

Обязанность родителей по содержанию детей носит практически безоговорочный, или абсолютный характер (Так, например, в немеиком семейном праве, 8 сравнении с общими обязательствами по финансовой поддержке родственников по прямой линии (\$ 1601 Гражданского уложения), обязательство по содержанию собственных несовершеннолетних детей является безоговорочным (\$ 1602 (2), 1603 (2) Гражданского уложения), так как в отличие от обязательства по финансовой поддержке родственников оно существует и в том случае если у обязанного лица нет возможности предоставить средства без риска для собственного надлежащего содержания (§ 1602)), что отличает ее от аналогичного института, существовавшего в древние времена, а также от института по содержанию родственников, не являющихся детьми. Действительно, единственным и наиболее распространённым условием обязанности родителей по содержанию детей является несовершеннолетие последних: несовершеннолетие является единственным общим основанием возникновения обязанности родителей по содержанию детей в различных государствах (Стоит отметить, что подход мусульманских государств не всегда однозначен в данном вопросе и варьируется в частности от пола ребенка. Так, например, в алжирском семейном праве обязанность родителей по содержанию собственных детей прекращается в случае с детьми мужского пола с наступлением совершеннолетия последних. В свою очередь, если речь идет о детях женского пола такая обязанность прекращается с выходом дочери за муж. Данный факт явным образом свидетельствует о неравенстве полов в мусульманских государствах и отражении таких культурных особенностей мусульманских государств в правовом регулировании вопросов семейного права. См. подробнее по данному вопросу, например: Nahas M. Mahieddin, L'évolution du droit de la famille en Algérie : nouveautés et modifications apportées par la loi du 4 mai 2005 au Code algérien de la famille du 9 juin 1984, L'année du Maghreb, 2005. pp. 97-137). Тем не менее, в отдельных государствах существует несколько иной подход, который на наш взгляд более справедлив в подходе к решению данной проблемы: речь идет об обязанности по содержанию не несовершеннолетних детей вообще, а только несовершеннолетних детей, не имеющих достаточных собственных средств (Стоит отметить, что в российской науке семейного права мы можем обнаружить аналогичные утверждения. Так, например, Шерстнева Н.С. пишет: «Разрешая споры о снижении или увеличении размера алиментов, взысканных на несовершеннолетних детей, суд вправе отказать полностью или частично в удовлетворении соответствующих требований, поскольку закон предусматривает возможность, а не обязанность их удовлетворения». См.: Шерстпева К.С. Взыскание алиментов на несовершеннолетних детей в твердой денежной сумме. // Российская юстищия. - 2006. № 6. - C. 25). Очевидным образом, данное условие свидетельствует о том, что обязанность родителей по содержанию собственных детей связана с объективной невозможностью детей содержать себя за счет 
DOI: $10.7256 / 1811-9018.2015 .9 .16171$

При цитировании этой статьи сноска на доі обязательна

\section{Право и политика 9 (189) • 2015}

собственных средств (Наиболее явным образом это выражено $n .1 \mathrm{~cm} .75$ Алжирского семейного кодекса, где однозначно указывается, что такая обязанность существует в случае если у ребенка нет собственных средств. См. Loi $N^{\circ}$ 84-11 portant Code de la Famille. Journal Officiel de la République algérienne, oct./nov. 1983, p. 612.). Подтверждение этому мы можем обнаружить в калифорнийском семейном кодексе (§ 3901 (1)), где в частности указывается, что обязанность по поддержанию детей продолжается и после 18-ти летнего возраста (до достижения 19-ти лет) в случае если ребенок является «... студентом очной формы обучения и не содержит себя сам...». Таким образом, обязанность родителей по содержанию несовершеннолетних детей существует в связи с презумпцией отсутствия у них наличия собственных средств за невозможностью осуществления трудовой деятельности ввиду ограниченной дееспособности (Напомним, что одним из условий эмансипации несовершеннолетнего лица является занятие трудовой деятельностью (ст. 21 n. 2 ГК РФ), которое в принципе должно позволить обеспечить лииу себя средствами и, как следствие, снять с родителя обязанность по содержанию несовершеннолетних, но эмансипированных детей).

Данное утверждение подтверждается и отдельными условиями освобождения родителей от рассматриваемой обязанности. Действительно, эмансипация ребенка или приобретение им полной дееспособности при вступлении в ранний брак по российскому праву приводит (пп. 1 и 2 ст. 120 Семейного кодекса РФ) к снятию обязанности по содержанию детей. В свою очередь, алжирский законодатель еще более однозначен, так как установление такой обязанности ограничено случаями, когда у детей нет собственных средств на содержание и она прекращает свое действие как только ребенок располагает достаточными средствами, необходимыми для собственного содержания (пп. 3 и 4 ст. 75 алжирского Семейного кодекса). Немецкий законодатель также более справедлив, на наш взгляд, чем российский законодатель, так как в ФРГ обязанность родителей по содержанию несовершеннолетних детей связана не с недееспособностью (отсутствием совершеннолетия) последних, а с наличием или отсутствием у них средств (§ 1602 Гражданского уложения). Действительно, обязанность родителей по содержанию несовершеннолетних детей связана с объективной нуждой, а не с гипотетической возможностью детей осуществлять трудовую деятельность. Как следствие, подход алжирского и немецкого законодателя к данному вопросу более прагматичен на наш взгляд.
Несмотря на наличие в российском праве такого обстоятельства, освобождающего лицо от обязанности по содержанию несовершеннолетних детей, как вступление последних в брак его нельзя признать повсеместным (ст. 120 Семейного кодекса): так, например, мы его не обнаружим в калифорнийском семейном праве. В тоже время, такое основание освобождения родителя от рассматриваемой обязанности существует в немецком праве, где предусматривается, что если несовершеннолетний состоит в браке или зарегистрированном партнерстве, то его содержание осуществляется, в первую очередь, не за счет родителей, а супруга (сожителя), тогда как родители будут обязаны его содержать лишь в случае недостаточных средств у супруга (§ 1608 Гражданского уложения). Такое исключение из обязательства родителей, по всей видимости, связано с тем, что ответственность по содержанию ребенка здесь переходит с родителя на супруга, а родители (как в немецком праве) носят лишь субсидиарную обязанность [8]. Ситуация здесь аналогична усыновлению (удочерению), при котором все обязанности переносятся с плеч родителя на усыновившего (удочерившего) (Cм. $n$. 17 Постановления Пленума Верховного суда РФ от 20 апреля 2006 года № 8 “О применении судами законодательства при рассмотрении дел об усыновлении (удочерении) детей” (Российская газета от 3 мая 2006 г. № 4058), где указывается что с родителя усыновленного снимается обязанность уплаты алиментов).

В отдельных (мусульманских) странах такое исключение из рассматриваемой обязанности касается только детей женского пола: в алжирском семейном праве (ст. 75 алжирского семейного кодекса) родители освобождаются от обязанности содержать собственную дочь с ее выходом замуж, что предполагает как их освобождение от данной обязанности до наступления ее совершеннолетия, так и продления данной обязанности после наступления совершеннолетия (в случае если к этому времени дочь не вышла замуж). Такой дискриминационный подход к указанной обязанности родителей свидетельствует о высоко патриархальном складе алжирского семейного права.

Содержание несовершеннолетних детей осуществляется посредством предоставления алиментов, размер которых может быть установлен консенсуально, т.е. посредством соглашения родителей (п. 1 ст. 80 Семейного кодекса). Порядок исчисления сумм алиментов (т.е. содержания), подлежащих взысканию на несовершеннолетних детей, в отсутствии соглашения родителей установлен законом. В принципе, он устанав- 
ливается в размере определенных долей от заработка родителя (Понятие заработка родителя является довольно широким. См. Постановление Правительства РФ от 18 июля1996 года № 841 “О перечне видов заработной платы и иного дохода, из которых производится удержание алиментов на несовершеннолетних детей"// Собрание законодательства Российской Федерациии, 1996, № 31, cm. 3743) в зависимости от количества детей, нуждающихся в содержании: от одной четверти (в случае если речь идет о содержании одного ребенка) до половины заработка (в случае если речь идет о содержании трех и более детей). В исключительных случаях содержание несовершеннолетнего ребенка исчисляется в твердой денежной сумме (ст. 83 Семейного кодекса).

Стоит отметить, что подобного подхода к определению уровня участия родителя в содержании несовершеннолетних детей в зарубежных государствах нами обнаружено не было. Так, например, в американском гражданском законодательстве различных штатов не устанавливается такого подробного регулирования уровня расходов, которые обязан выделить родитель на содержание собственного ребенка (§ 3900-3952 калифорнийского Семейного кодекса). Здесь данный вопрос оставляется на усмотрение родителей и, в крайнем случае, суда (§ 4000-4250). Аналогичен подход к определению размера алиментов и в других государствах, что наш взгляд является более справедливым подходом, так как позволяет - как, например, и прогрессивный налог в налоговом праве - учесть финансовую ситуацию конкретного обязанного субъекта (Наиболее ярким примером здесь может служить немеикое Гражданское уложение, где, в частности, указывается, что обязанность по содержанию налагается на лиио в зависимости от его средств (§ 1603 (1)). См. подробнее, например: Terpitz W. Terpitz J. Rechte der Jugendlichen von A-Z zwischen 14 und 18. 3e Auflage: Deutschen Taschenbuch. 2000. S. 34.).

Стоит отметить, что в российском праве размер указанных директивным образом долей может быть изменен. В тоже время законодатель однозначно дал понять, что речь идет об изменении размера алиментов в судебном порядке (ст. 81 Семейного кодекса) в случае отсутствия соглашения об уплате алиментов. Несмотря на данное указание российский законодатель - в сравнении с западными примерами - довольно жестко определил размер обязанности родителей по содержанию несовершеннолетних детей. Действительно, если учесть, что к судебному порядку разрешения споров в России прибегают нечасто (в том числе и по рассматри- ваемой категории дел), то мы можем утверждать, что на практике, в большинстве случаев, размер алиментов соответствует указанному в законе принципу долей, а не материальному и семейному положению сторон или иным обстоятельствам. Последние учитываются в судебном порядке лишь тогда, когда обязательство по содержанию несовершеннолетних детей существует в отношении нескольких, проживающих раздельно детей и суду предстоит определить конкретные доли заработка родителя в отношении каждого из них: только в таких случаях чаще всего учитываются семейное и материальное положение субъектов (Cтоит отметить, что судебная практика формальна и в данных случаях, так как чаще всего при распределении обязательств родителя по содержанию нескольких детей используются указанные в $n .1 \mathrm{~cm} .81$ Семейного кодекса доли. См. подробнее по данному вопросу, например: Судебная практика по семейным спорам. Книга 1. // Под руководством Крашенникова П.В. - М., - 2004. - С. 120).

В свою очередь, в традиционных мусульманских государствах обязанности родителей по содержанию собственных детей довольно часто смешиваются с обязательством супруга поддерживать бывшую жену после развода. Действительно, например, алжирский семейный кодекс обязывает бывшего мужа выплачивать своей бывшей жене ренту в течении нескольких месяцев после развода (ст. 61), а также в случае если дети от брака проживают с ней (подавляющее большинство случаев) обеспечить бывшую супругу, и как следствие своих детей, жильем (ст. 72) (См. решение алжирского Верховного суда: Cour suprême, 16 février 1999, al-Madjalla al-qadâ'iyya, 2000).

Подобный подход существует и в немецком праве, где помимо обязательства по содержанию собственных детей, цель по их обеспечению необходимыми средствами также достигается и с помощью различных мер, направленных на обеспечение бывшего супруга, с которым проживают дети. Более того, немецкий законодатель пошел намного дальше, создав с данной целью в Гражданском уложении специальную главу (Данная глава (Untertitel 2 «Besondere Vorschriften für das Kind und seine nicht miteinander verheirateten Eltern») появилась в гражданском уложении на рубеже тысячелетий и была создана с ичелью защчиты прав ребенка рожденного от родителей не состоящчих в браке. Cм. подробнее, например: R. Hоррепz, G. Brudermüller, Familiensachen, Hüthig Jehle Rehm, 2009.). Так, например, будущий отец может быть обязан содержать мать в течении шести недель до рождения ребенка и восьми недель после его рождения и участвовать в расходах, 
DOI: 10.7256/1811-9018.2015.9.16171

При цитировании этой статьи сноска на dоі обязательна

\section{Право и политика 9 (189) • 2015}

связанных с беременностью (§ 1615 (1)). Также, если мать ребенка не способна осуществлять трудовую деятельность в связи с беременностью или уходом за ребенком отец обязан предоставлять ей содержание на период, начинающийся не ранее четырех месяцев до рождения ребенка и длящийся как минимум до трех лет после его рождения (§ 1615 L (2) Гражданского уложения Германии). Наконец, кончина матери связанная с беременностью также накладывает на отца и расходы по ее погребению (§ $1615 \mathrm{~m})$. Очевидно, что указанные положения немецкого гражданского права свидетельствуют о серьезности подхода немецкого законодателя к ответственности отца, что довольно удивительно для государства, в котором система социального обеспечения (в том числе матери и ребенка) развита наибольшим образом, т.е. где защита прав и интересов граждан обеспечена государством в наиболее полном объеме.

Интересен и подход калифорнийского законодателя к определению размера алиментов. Напомним, что здесь как и в подавляющем большинстве зарубежных государств в семейном законодательстве не установлено порядка определения размера алиментов. В тоже время, здесь (§ 4004 калифорнийского семейного кодекса) при определении размера алиментов учитывается размер социального обеспечения, выделяемого на ребенка штатом в соответствии с рядом нормативных актов, касающихся социального и семейного обеспечения (public assistance under the Family Economic Security Act of 1982 and Welfare and Institutions Code), а также законодательства о медицинском страховании (health insurance coverage) (§ 4006 калифорнийского семейного кодекса). Данный подход справедлив на наш взгляд, так как позволяет осуществить более точную оценку нужды ребенка и с точностью определить количество средств, предоставляемых ему в том числе и органами опеки и социального обеспечения и избежать необоснованного обогащения родителей с которыми проживают данные дети [3].

Аналогичен и подход немецкого законодателя, который при определении размера алиментов также учитывает все выдаваемые на ребенка социальные пособия [7]. В тоже время стоит также обратить внимание и на отдельную особенность немецкого подхода в определении размера алиментов. Здесь, при определении размера алиментов, в частности, учитывается возраст ребенка. Конкретно это выражается в идее роста потребностей ребенка с его взрослением, т.е. по немецкому праву размер алиментов должен изменяться в зависимости от возраста ребенка и постоянно увеличиваться вплоть до его совершеннолетия, так как предполагается, что его потребности постоянно растут.

$$
* * *
$$

Таким образом, обязанности родителей по содержанию несовершеннолетних детей являются наиболее устоявшимся институтом семейного права любого государства. Наиболее серьезные различия в данном вопросе существуют между, с одной стороны, странами мусульманской правовой семьи, а, с другой стороны, странами романо-германской и англосаксонской правовых семей. В тоже время, различия между ними довольно относительны и выражаются, в первую очередь, в неравенстве полов по отношению к обязанности по содержанию несовершеннолетних детей.

\section{Библиография:}

1. Перетерский И. С. Дигесты Юстиниана (пер. Перетерский И. С.). - М. - Наука. - 1984. С. 520.

2. Шерстпева К.С. Взыскание алиментов на несовершеннолетних детей в твердой денежной сумме. // Российская юстиция. - 2006. - № 6. - C. 25.

3. T. Haet. California Child and Spousal Support: Establishing, Modifying, and Enforcing. - CEB, -2014 . -358 p.

4. R. Hoppenz, G. Brudermüller, Familiensachen, Hüthig Jehle Rehm, 2009.

5. Nasreddin Marrûk, Qânûn al-usra bayn al-nadhariyya wa al-tatbîq, Alger, Dâr al-Hilâl li-1-khadamât al-i’lâmiyya, 2204, p. 120

6. Nahas M. Mahieddin, L'évolution du droit de la famille en Algérie : nouveautés et modifications apportées par la loi du 4 mai 2005 au Code algérien de la famille du 9 juin 1984, L'année du Maghreb, 2005. pp. 97-137

7. K. Schellhammer. Familienrecht nach Anspruchsgrundlagen: samt Verfahren in Familien-, Kindschafts-und Betreuungssachen. - C.F. Muller, $-2006-797$ p.

8. C. Schmid, Stiftungsrechtliche Zuwendungen Im Erb-und Familienrecht: Pflichtteilsergänzung und Zugewinnausgleich. - BWV Verlag, - 2010. - 228 .

9. Terpitz W. Terpitz J. Rechte der Jugendlichen von A-Z zwischen 14 und 18. 3e Auflage: Deutschen Taschenbuch. 2000. S. 34.

10. А. Магомедов (ред.), Коран, изд. «Диля», Сура 4, «Ан Ниса», 5

11. П. Барнетт, Второе послание к Коринфянам, 2002, СПб, гл. 12, 14

12. Пространная редакция Русской Правды // Российское законодательство X-XX веков. Т.1. М., Юридическая литература. 1984. C.64-73. 
DOI: $10.7256 / 1811-9018.2015 .9 .16171$

При цитировании этой статьи сноска на dоі обязательна

Человек и государство

\section{References (transliterated):}

1. Pereterskii I. S. Digesty Yustiniana (per. Pereterskii I. S.). - M. - Nauka. - 1984. S. 520.

2. Sherstpeva K.S. Vzyskanie alimentov na nesovershennoletnikh detei v tverdoi denezhnoi summe. // Rossiiskaya yustitsiya. 2006. - № 6. - S. 25.

3. T. Haet. California Child and Spousal Support: Establishing, Modifying, and Enforcing. - CEB, - 2014. - 358 r.

4. R. Hoppenz, G. Brudermüller, Familiensachen, Hüthig Jehle Rehm, 2009.

5. Nasreddin Marrûk, Qânûn al-usra bayn al-nadhariyya wa al-tatbîq, Alger, Dâr al-Hilâl li-1-khadamât al-i'lâmiyya, 2204, p. 120

6. Nahas M. Mahieddin, L'évolution du droit de la famille en Algérie : nouveautés et modifications apportées par la loi du 4 mai 2005 au Code algérien de la famille du 9 juin 1984, L’année du Maghreb, 2005. pp. 97-137

7. K. Schellhammer. Familienrecht nach Anspruchsgrundlagen: samt Verfahren in Familien-, Kindschafts-und Betreuungssachen. - C.F. Muller, $-2006-797$ p.

8. C. Schmid, Stiftungsrechtliche Zuwendungen Im Erb-und Familienrecht: Pflichtteilsergänzung und Zugewinnausgleich. - BWV Verlag, - 2010. - 228 .

9. Terpitz W. Terpitz J. Rechte der Jugendlichen von A-Z zwischen 14 und 18. 3e Auflage: Deutschen Taschenbuch. 2000. S. 34.

10. A. Magomedov (red.), Koran, izd. «Dilya», Sura 4, «An Nisa», 5

11. P. Barnett, Vtoroe poslanie k Korinfyanam, 2002, SPb, gl. 12, 14 